Este artigo é apresentado em Português e Inglês com o "Resumen" em Espanhol.

Revista Brasileira de Tecnologia Aplicada nas Ciências Agrárias, Guarapuava-PR, v. 4, n.3, p.67-82, 2011.

\section{Artigo Científico}

\section{Resumo}

O objetivo do trabalho foi avaliar a influência da forma de aplicação e doses de adubação com NPK nos custos de produção e rentabilidade da cultura da batata na Região Centro-Oeste do Estado do Paraná. O trabalho foi conduzido em Latossolo Bruno Distrófico no município de Pinhão com altitude de $1.131 \mathrm{~m}$ e coordenadas de $25^{\circ} 42^{\prime} 00^{\prime \prime}$ S e $51^{\circ} 46^{\prime} 00^{\prime \prime}$ W. Utilizou-se a variedade Monalisa. O delineamento

\title{
Influência da adubação com NPK na produção comercial e rentabilidade da batata na região Centro-Oeste do Paraná
}

Nicolau Mallmann ${ }^{2}$ Luis Antônio Correa Lucchesi $i^{3}$ Cícero Deschamps ${ }^{3}$ experimental foi blocos ao acaso com 18 tratamentos e 4 repetições. Os tratamentos consistiram de doses de $\mathrm{N}$ como fonte a uréia, com e sem parcelamento, mantendo-se constantes as doses de $\mathrm{P}_{2} \mathrm{O}_{5}$ e de $\mathrm{K}_{2} \mathrm{O}$; doses crescentes de $\mathrm{P}_{2} \mathrm{O}_{5}$, utilizando o super fosfato triplo, mantendo-se constantes as doses de $\mathrm{Ne} \mathrm{K}_{2} \mathrm{O}$; e de doses crescentes de $\mathrm{K}_{2} \mathrm{O}$, utilizando-se duas fontes de potássio, $\mathrm{KCl}$ e $\mathrm{K}_{2} \mathrm{SO}_{4^{\prime}}$ para os quais também mantiveram-se constantes as doses de $\mathrm{N}$ e de $\mathrm{P}_{2} \mathrm{O}_{5}$. Como testemunha empregou-se doses de N, $\mathrm{P}_{2} \mathrm{O}_{5}$ e $\mathrm{K}_{2} \mathrm{O}\left(120-420-240 \mathrm{~kg} \mathrm{ha}^{-1}\right)$ tradicionalmente utilizadas na região. Verificou-se que a adubação potássica da cultura da batata na região Centro-Oeste do Paraná resulta na máxima receita líquida quando a fórmula tradicional $120 \mathrm{~N}-420 \mathrm{P}_{2} \mathrm{O}_{5}-240 \mathrm{~K}_{2} \mathrm{O}(\mathrm{KCl}) \mathrm{kg} \mathrm{ha}^{-1}$ é ajustada para $120 \mathrm{~N}-420 \mathrm{P}_{2} \mathrm{O}_{5}-560 \mathrm{~K}_{2} \mathrm{O}\left(\mathrm{K}_{2} \mathrm{SO}_{4}\right) \mathrm{kg}$ ha $^{-1}$. A adubação nitrogenada com aplicação de $120 \mathrm{~kg}_{\text {de }} \mathrm{N} \mathrm{ha}^{-1}$ é uma alternativa com maior viabilidade quando o nutriente é aplicado $2 / 3$ na base e $1 / 3$ em cobertura. A quantidade de fósforo deve levar em consideração o objetivo da lavoura, sendo que o aumento da dosagem favorece as lavouras de produção de batata-semente.

Palavras-chave: Solanum tuberosum L.; produtividade comercial; adubação e rendimento

\section{Influencia de la fertilización con NPK con en la producción comercial y rentabilidad de la papa en el región centro-oeste del estado de Paraná}

\section{Resumen}

El objetivo de este estudio fue evaluar la influencia del tipo de aplicación y dosis de fertilización NPK en los costos de producción y la rentabilidad del cultivo de papa (patata) en la región del Centro-Oeste del Estado de Paraná/Brasil. El estudio se realizó en Latossolo Bruno Distrófico en Pinhão con altitud de $1.13 \mathrm{~m}$ y coordinadas de $25^{\circ} 42^{\prime} 00^{\prime \prime} \mathrm{S}$ y $51^{\circ} 46^{\prime}$ $00^{\prime \prime}$ W. Se utilizó la variedad de patata Monalisa. El diseño experimental fue bloques al azar con 18 tratamientos y cuatro repeticiones. Los tratamientos consistieron de $\mathrm{N}$ en forma de urea, con y sin fragmentación, manteniéndose constantes las dosis de $\mathrm{P}_{2} \mathrm{O}_{5}$ y de $\mathrm{K}_{2} \mathrm{O}$; dosis crecentes de $\mathrm{P}_{2} \mathrm{O}_{5^{\prime}}$ utilizando el superfosfato triple permanecido constantes las dosis de $\mathrm{N}$ y $\mathrm{K}_{2} \mathrm{O}$; y el aumento de dosis de $\mathrm{K}_{2} \mathrm{O}$ utilizando dos fuentes de potasio, $\mathrm{KCl}$ e $\mathrm{K}_{2} \mathrm{SO}_{4^{\prime}}$ para lo cual también se mantuvieron constantes las dosis de $\mathrm{N} \mathrm{y}_{2} \mathrm{O}_{5}$. Como control, se utilizaron dosis de $\mathrm{N}, \mathrm{P}_{2} \mathrm{O}_{5}$ y de $\mathrm{K} 2 \mathrm{O}$ (120-420-240 kg ha-1) utilizados tradicionalmente en la región. Se encontró que la fertilización potásica en el cultivo de la papa en la región centro-oeste del Paraná resulta en lo máximo ingreso netos cuando la fórmula tradicional $120 \mathrm{~N}-420 \mathrm{P}_{2} \mathrm{O}_{5}-240 \mathrm{~K}_{2} \mathrm{O}(\mathrm{KCl}) \mathrm{kg} \mathrm{ha}^{-1} \mathrm{es}$ ajustada para $120 \mathrm{~N}-420 \mathrm{P}_{2} \mathrm{O}_{5}-560 \mathrm{~K}_{2} \mathrm{O}\left(\mathrm{K}_{2} \mathrm{SO}_{4}\right) \mathrm{kg} \mathrm{ha}^{-1}$. La aplicación de la fertilización nitrogenada con $120 \mathrm{~kg} \mathrm{~N} \mathrm{ha}^{-1}$ es una alternativa más viable cuando el nutriente es aplicado $2 / 3$ en lo plantío y $1 / 3$ como abono de cobertura. La cantidad de fósforo debe tomar en consideración el propósito de lo cultivo, y el aumento de la dosis favorece la producción en los cultivos de papas de siembra.

Palavras-llave: Solanum tuberosum L.; produtividad; abono; patata

\section{Introdução}

No Centro-Oeste Paranaense o cultivo da batata iniciou-se com a vinda de imigrantes europeus, principalmente poloneses e alemães, na década de 1930, ainda que em escala de subsistência. Nessa região a cultura é preferencialmente cultivada em áreas originalmente mantidas sob pastagem nativa 
ou em rotação com lavouras de soja, milho, trigo ou cevada.

As práticas de adubação empregadas no cultivo da batata no Brasil são bastante assemelhantes, apesar das diferenças existentes entre as condições climáticas e edáficas nas diversas regiões, sendo basicamente traduzida na aplicação, por hectare, de $160 \mathrm{~kg}$ de $\mathrm{N}, 560 \mathrm{~kg}$ de $\mathrm{P}_{2} \mathrm{O}_{5}$ e $320 \mathrm{~kg}$ de $\mathrm{K}_{2} \mathrm{O}(\mathrm{KCl})$ para áreas de primeiro ano e 120, 420 e $240 \mathrm{~kg} \mathrm{ha}^{-1}$ desses nutrientes para áreas já cultivadas anteriormente.

A taxa de absorção de nutrientes pelos vegetais é governada pela concentração externa e pela sua demanda em função do desenvolvimento das plantas e atividade dos seus diversos órgãos. A taxa de absorção de água e de minerais é também influenciada por diversos fatores como a cultivar, condições climáticas, condições de solo onde enquadra-se a disponibilidade suprimento de nutrientes a ex:. N, K, Cl e de P (BEUKEMA e ZAAG, 1990; JADOSKI, et al., 2010).

O nível de nutrientes na solução do solo deve ser suficiente para não limitar a taxa de absorção e o crescimento das plantas. Por outro lado, a concentração de nutrientes demasiadamente alta em solução pode induzir a redução no crescimento devido a toxidez ou à interferência de certos elementos na absorção de outros nutrientes pelas plantas (FONTES, 1987). Dessa forma é importante que se avalie e calibre a aplicação de doses de nutrientes em solos para a cultura da batata com os seus respectivos custos e rentabilidade.

A assimilação do nitrogênio pela planta de batata é maior quando alcança a altura de 20 a 30 $\mathrm{cm}$, fase em que o teor de $\mathrm{N}$ pode superar $4 \%$ da matéria seca da planta. $\mathrm{O}$ teor de $\mathrm{N}$ na folhagem da batata diminui gradativamente quando começa a tuberização (ZAAG, 1993). Estima-se que para as condições da Região Centro-Oeste do Estado Paraná a máxima absorção de nitrogênio provavelmente ocorra entre 30 a 50 dias após o plantio. No desenvolvimento máximo a quantidade total de $\mathrm{N}$ nas plantas é entorno de $200 \mathrm{~kg} \mathrm{ha}^{-1}$ (soma da parte aérea e tubérculos).

A produção de tubérculos ocorre num curto período, simultaneamente ao desenvolvimento da parte aérea. Doses muito altas de nitrogênio aplicadas tardiamente, juntamente com excesso de água nessa fase, induzem a planta a prolongar seu crescimento vegetativo e reduzir o período de tuberização desejável, resultando em menor produtividade (BEUKEMA e ZAAG, 1990; ZAAG, 1993; FONTES, 1987).
Segundo ZAAG (1986) a aplicação de altas doses de $\mathrm{N}$ na cultura da batata pode induzir a redução dos teores de matéria seca e aumento nos teores de açúcares redutores e de proteínas nos tubérculos, particularmente quando do uso de nitratos e principalmente quando a dessecação da parte aérea é efetuada antes da maturação dos tubérculos. Dependente de algumas variedades, MENGUEL e KIRKBY (1987) citam que altas doses de $\mathrm{N}$ podem induzir a um crescimento secundário em tubérculos após um período de deficiência hídrica.

O fósforo é assimilado mais intensamente pela planta no estágio de desenvolvimento vegetativo. O teor de fósforo no caule e nos tubérculos atinge aproximadamente $0,7 \%$ da matéria seca, o equivalente a $60 \mathrm{~kg} \mathrm{ha}{ }^{-1}$ de $\mathrm{P}_{2} \mathrm{O}_{5}$, dos quais $50 \mathrm{~kg}$ de $\mathrm{P}_{2} \mathrm{O}_{5} \mathrm{ha}^{-1}$ encontram-se nos tubérculos logo após o arranquio (ZAAG, 1993; BEUKEMA e ZAAG, 1990). Para uma produção de tubérculos de $25 \mathrm{Mg} \mathrm{ha}^{-1}$ a exigência total de fósforo pela cultura é estimada entorno de $11,68 \mathrm{~kg} \mathrm{ha}^{-1}$ de $\mathrm{P}_{2} \mathrm{O}_{5}$, sendo que desse total as ramas concentram 4,58 kg ha-1 de $\mathrm{P}_{2} \mathrm{O}_{5}$ e os tubérculos 7,10 $\mathrm{kg} \mathrm{ha}^{-1}$ (MALAVOLTA e CROCOMO, 1982).

O fósforo tem influência significativa na redução do ciclo vegetativo e no aumento do número de tubérculos por planta, mas pouco contribui para o aumento da produtividade comercial e para tamanho do tubérculo (FONTES, 1999; ZAAG, 1993). O fósforo não tem efeito notável sobre a produção de matéria seca, a não ser quando aplicado em doses excessivamente altas. A deficiência de fósforo ocorre de forma mais marcante em solos arenosos, ácidos, pobres em matéria orgânica e também está associada a adubação nitrogenada deficiente.

Quando os plantios de batata são feitos em áreas já cultivadas, a quantidade de fósforo a ser aplicada depende da análise de solo que deverá estimar o nível de fósforo já existente e conforme sua textura. Solos de textura média e arenosa necessitam apresentar maior teor de $\mathrm{P}$ extraível do que os de textura argilosa para serem considerados como detentores de menores teores disponíveis de P (FONTES,1987).

O potássio afeta a produtividade com doses adequadas e influencia na qualidade da produção, em características como tamanho e teor de matéria seca do tubérculo, resistência a danos mecânicos, escurecimento após o cozimento e qualidade durante o armazenamento (BEUKEMA e ZAAG, 1990).

No estádio de máximo desenvolvimento da parte aérea, o teor de potássio pode variar 


\author{
Influência da adubação com NPK na produção... \\ Influencia de la fertilización con NPK con en la producción... \\ Influence in the fertilization with NPK in production..
}

próximo a $7 \%$ da matéria seca, o que corresponde a aproximadamente $420 \mathrm{~kg} \mathrm{ha}^{-1}$ de $\mathrm{K}_{2} \mathrm{O}$. Na colheita, os tubérculos contém em média valores que variam de $1,5 \%$ a $2,5 \%$ da matéria seca em $\mathrm{K}_{2} \mathrm{O}$. A taxa de assimilação máxima de potássio pelas plantas coincide com o pico de desenvolvimento da parte aérea (ZAAG, 1993). Para uma produtividade de 25 $\mathrm{Mg} \mathrm{ha}^{-1}$ de tubérculos a exigência total de $\mathrm{K}_{2} \mathrm{O}$ é de $165 \mathrm{~kg} \mathrm{ha}^{-1}$, sendo que destes em torno de $75 \mathrm{~kg} \mathrm{ha}^{-1}$ estão contidos nos tubérculos e $90 \mathrm{~kg} \mathrm{ha}^{-1}$ nas ramas (MALAVOLTA e CROCOMO, 1982).

O sulfato de potássio e o cloreto de potássio diferem nos efeitos produzidos sobre as plantas. Isto, em parte, é explicado pelo ânion acompanhante $\left(\mathrm{SO}_{4}{ }^{2-}\right.$ ou $\left.\mathrm{Cl}^{-}\right)$ao cátion principal $\left(\mathrm{K}^{+}\right)$, afetando o comportamento deste e de outros cátions, bem como de maneira direta o metabolismo das plantas de batata. Algumas variedades são sensíveis ao cloreto. A utilização do sulfato de potássio proporciona melhor qualidade dos tubérculos, justificando a sua aplicação quando os tubérculos destinam-se para processamento industrial (MENGUEL e KIRKBY, 1987).

O sulfato de potássio geralmente é mais eficiente na promoção do acúmulo de matéria seca e de amido nos tubérculos do que o cloreto de potássio, particularmente em dias em que a intensidade luminosa é mais acentuada. No entanto, em dias com menor luminosidade o cloreto de potássio pode tornar-se mais eficiente para tal (ZEHLER,1981).

Apesar de o cloro ser um micronutriente essencial, a batata é uma espécie clorófoba. O efeito negativo do cloro sobre a batateira é mais evidente em solos arenosos do que em solos argilosos, possivelmente por estes serem menos tamponados. Desta forma, deve-se levar em conta que o $\mathrm{K}_{2} \mathrm{O}$ fornecido em grandes quantidades na forma de cloreto tende a reduzir o teor de matéria seca (BEUKEMA e ZAAG, 1990).

$\mathrm{Na}$ batata o teor de matéria seca, o peso específico e teor de amido dos tubérculos determinam a qualidade. Tais fatores são influenciados pelo tipo de adubo potássico utilizado. Se de um lado os efeitos são positivos do Kna translocação de carboidratos, no sistema enzimático, na produtividade e na qualidade são, até certo ponto, contrabalançados por alguns efeitos desfavoráveis devidos ao aumento do teor de potássio na planta que, em altas doses, pode reduzir o teor de amido no tubérculo (STRUIK e WIERSEMA, 1999; MENGUEL e KIRKBY, 1987; MARSCHNER, 1993).

CHAVES e PEREIRA (1985) verificaram que a adubação potássica, quando efetuada proximamente ao plantio e efetuada à base de cloreto de potássio foi prejudicial à planta, pois a assimilação de íons $\mathrm{Cl}^{-}$afetou as combinações orgânicas do $\mathrm{P}$, portanto, dos carboidratos. Também foi verificado que enzimas hidrolíticas que participaram da translocação de carboidratos, tinham sua atividades reduzidas.

O objetivo da pesquisa foi avaliar a influência da forma de aplicação e doses de adubação com NPK nos custos de produção e rentabilidade da cultura da batata na Região Centro-Oeste do Estado do Paraná.

\section{Material e Métodos}

O trabalho foi conduzido em área de Latossolo Bruno Distrófico (EMBRAPA, 1999), no município de Pinhão, na Região Centro-Oeste do Estado do Paraná, com altitude de $1.131 \mathrm{~m}$ e coordenadas geográficas $25^{\circ} 42^{\prime} 00^{\prime \prime}$ S e $51^{\circ} 46^{\prime} 00^{\prime \prime} \mathrm{W}$. O clima da região é classificado como subtropical Cfb (IAPAR, 1999). A precipitação pluviométrica mensal média no período do experimento foi de $133 \mathrm{~mm}$, a temperatura média de $20,4^{\circ} \mathrm{C}$ e a umidade relativa de $75 \%$.

O experimento foi instalado junto a uma cultura de batata-consumo em sucessão à cultura da soja. Historicamente, a área foi cultivada pela primeira vez com batata e, em seguida, com arroz e por quatro anos com pastagem artificial de pensacola (Paspalum sp.). A área experimental foi preparada com duas arações, duas gradagens e uma escarificação. As parcelas foram constituídas por 4 sulcos de plantio cada um com 5,0 m de comprimento, espaçados entre si de $0,75 \mathrm{~m}$. O plantio foi realizado com a variedade Monalisa, no mês de outubro (safra das águas). Os tubérculos foram plantados manualmente, na densidade de 14 tubérculos por linha de $5 \mathrm{~m}$ de comprimento, obtendo-se um espaçamento médio de $0,35 \mathrm{~m}$ entre tubérculos.

O delineamento experimental utilizado foi o de blocos ao acaso com 18 tratamentos e 4 repetições, totalizando 72 parcelas. Os tratamentos consistiram de doses de $\mathrm{N}$ utilizando-se uréia, com e sem parcelamento, mantendo-se constantes as doses de $\mathrm{P}_{2} \mathrm{O}_{5}$ e de $\mathrm{K}_{2} \mathrm{O}$; de doses crescentes de $\mathrm{P}_{2} \mathrm{O}_{5}$, utilizando o super fosfato triplo, mantendo-se constantes as doses de $\mathrm{N}$ e $\mathrm{K}_{2} \mathrm{O}$; e de doses crescentes de $\mathrm{K}_{2} \mathrm{O}$, utilizando-se duas fontes de potássio, $\mathrm{KCl}$ e $\mathrm{K}_{2} \mathrm{SO}_{4}$, para os quais também mantiveram-se constantes as doses de $\mathrm{N}$ e de $\mathrm{P}_{2} \mathrm{O}_{5}$ (Tabela 1). Como testemunha empregou-se doses de N, $\mathrm{P}_{2} \mathrm{O}_{5}$ e $\mathrm{K}_{2} \mathrm{O}$ (120-420-240 kg $\left.\mathrm{ha}^{-1}\right)$, tradicionalmente utilizadas pelos produtores da Região Centro-Oeste do Estado do Paraná.

Pesquisa Aplicada \& Agrotecnologia v4 n3 set/dez. (2011)

Print-ISSN 1983-6325 (On line) e-ISSN 1984-7548 
Mallmann et al. (2011)

Tabela 1. Tratamentos de doses de nitrogênio $(\mathrm{N})$, fósforo $(\mathrm{P})$ e potássio $(\mathrm{K})$ e de fontes de potássio $(\mathrm{K})$ utilizados no experimento.

\begin{tabular}{|c|c|c|c|c|}
\hline Tratamentos & Doses & $\mathbf{N}$ & $\mathbf{P}_{2} \mathbf{O}_{5}$ & $\mathrm{~K}_{2} \mathrm{O}$ \\
\hline & & \multicolumn{3}{|c|}{ - } \\
\hline 1 & Testemunha & 120 & 420 & $240^{\mathrm{a}}$ \\
\hline 2 & $\mathrm{~N}($ Zero de $\mathrm{N})$ & 0 & 420 & $240^{\mathrm{a}}$ \\
\hline 3 & N (Uréia) & 80 & 420 & $240^{\mathrm{a}}$ \\
\hline 4 & N (Uréia) & $80+40^{*}$ & 420 & $240^{\mathrm{a}}$ \\
\hline 5 & N (Uréia) & $80+80 *$ & 420 & $240^{\mathrm{a}}$ \\
\hline 6 & $\mathrm{P}($ zero de $\mathrm{P})$ & 120 & 0 & $240^{\mathrm{a}}$ \\
\hline 7 & P (Super triplo) & 120 & 105 & $240^{\mathrm{a}}$ \\
\hline 8 & P (Super triplo) & 120 & 210 & $240^{\mathrm{a}}$ \\
\hline 9 & P (Super triplo) & 120 & 840 & $240^{\mathrm{a}}$ \\
\hline 11 & ${ }^{\mathrm{a}} \mathrm{K}$ (Cloreto de $\left.\mathrm{K}\right)$ & 120 & 420 & 120 \\
\hline 12 & ${ }^{\mathrm{a}} \mathrm{K}$ (Cloreto de K) & 120 & 420 & 480 \\
\hline 13 & ${ }^{\mathrm{a}} \mathrm{K}$ (Cloreto de $\left.\mathrm{K}\right)$ & 120 & 420 & 960 \\
\hline 14 & K (Zero de K) & 120 & 420 & 0 \\
\hline 15 & ${ }^{\mathrm{b}} \mathrm{K}$ (Sulfato de K) & 120 & 420 & 120 \\
\hline 16 & ${ }^{\mathrm{b}} \mathrm{K}$ (Sulfato de K) & 120 & 420 & 240 \\
\hline 17 & '⿳K (Sulfato de K) & 120 & 420 & 480 \\
\hline 18 & ${ }^{\mathrm{b}} \mathrm{K}$ (Sulfato de K) & 120 & 420 & 960 \\
\hline
\end{tabular}

${ }^{a} \mathrm{KCl} ; \quad{ }^{b} \mathrm{~K}_{2} \mathrm{SO}_{4} ; \quad$ parcelamento

As adubações foram efetuadas antes do plantio, à exceção dos tratamentos 4 e 5 , nos quais o adubo nitrogenado foi aplicado de forma parcelada, com $80 \mathrm{~kg} \mathrm{ha}^{-1}$ de $\mathrm{N}$ na base e o restante em cobertura, aos 30 dias após o plantio. Todas as parcelas receberam os mesmos tratos culturais, seguindo as práticas usualmente empregadas na região. A colheita foi realizada 120 dias após o plantio, considerando como área útil as duas linhas centrais da parcela.

A determinação da produtividade total e comercial foi realizada pelo método gravimétrico, extrapolando-se os valores obtidos para área de 1,0 ha. Para classificação comercial foram utilizados critérios do agronegócio regional da batata, onde os tubérculos são classficados na categorial comercial "especial" quando apresentam o menor diâmetro superior a $45 \mathrm{~mm}$ e ausência de defeitos na película externa. As demais categorias são classificadas como: a) diversa, b) primeira, c) $X, d$ ) segunda, e) pirulito e f) descarte. Nesse trabalho foi considerada apenas a categoria comercial "especial", devido que nas demais categorias o valor de mercado é normalmente inferior e, de forma geral, não cobre os custos de beneficiamento e embalagem.

Para o cálculo da receita líquida foi considerado o valor de $\mathrm{R} \$ 0,5998$ por $\mathrm{kg}$ de batata comercial, com base no orçamento de Custeio-2005/06 do Banco do
Brasil S.A. para Região do Centro-Oeste Paranaense, o qual reflete o valor comercial praticado na safra. $\mathrm{O}$ orçamento analítico (custo total) por hectare, sem o fertilizante foi de $\mathrm{R} \$ 8.017,46 \mathrm{ha}^{-1}$. Os custos por ponto de nutrientes foram plotados através da média dos preços praticados na região, sendo o ponto do $\mathrm{N}$ de $\mathrm{R} \$ 1,6022$; de $\mathrm{P}_{2} \mathrm{O}_{5}$ (TSP) de $\mathrm{R} \$ 1,5714$; de $\mathrm{K}_{2} \mathrm{O}(\mathrm{KCl})$ de $\mathrm{R} \$ 1,1116$; e de $\mathrm{K}_{2} \mathrm{O}\left(\mathrm{K}_{2} \mathrm{SO}_{4}\right)$ de $\mathrm{R} \$ 1,720$. A relação da moeda atualizada foi de R\$2,250 por US\$1,00.

Para o estabelecimento da relação entre custo de produção para máxima receita líquida considerouse os pontos de inflexão das curvas de resposta, para cada um dos nutrientes. Os procedimentos de cálculos foram estabelecidos através da relação matemática envolvendo a máxima produtividade multiplicada pelo valor de mercado $\left(\mathrm{R} \$ 0,5998 \mathrm{~kg}^{-1}\right)$, subtraindo-se deste produto o custo básico (com dose zero do nutriente considerado) e dividindo-se o montante total pelo valor do ponto do nutriente. Este resultado expressa a dosagem a ser aplicada do nutriente (associada a fórmula 120-420-240 kg $\mathrm{ha}^{-1}$ ) para obtenção da máxima receita líquida com a cultura.

\section{Resultados e discussão}

As diferentes doses de nitrogênio afetaram a produtividade da cultura. Através da Figura 01-I 
(l)
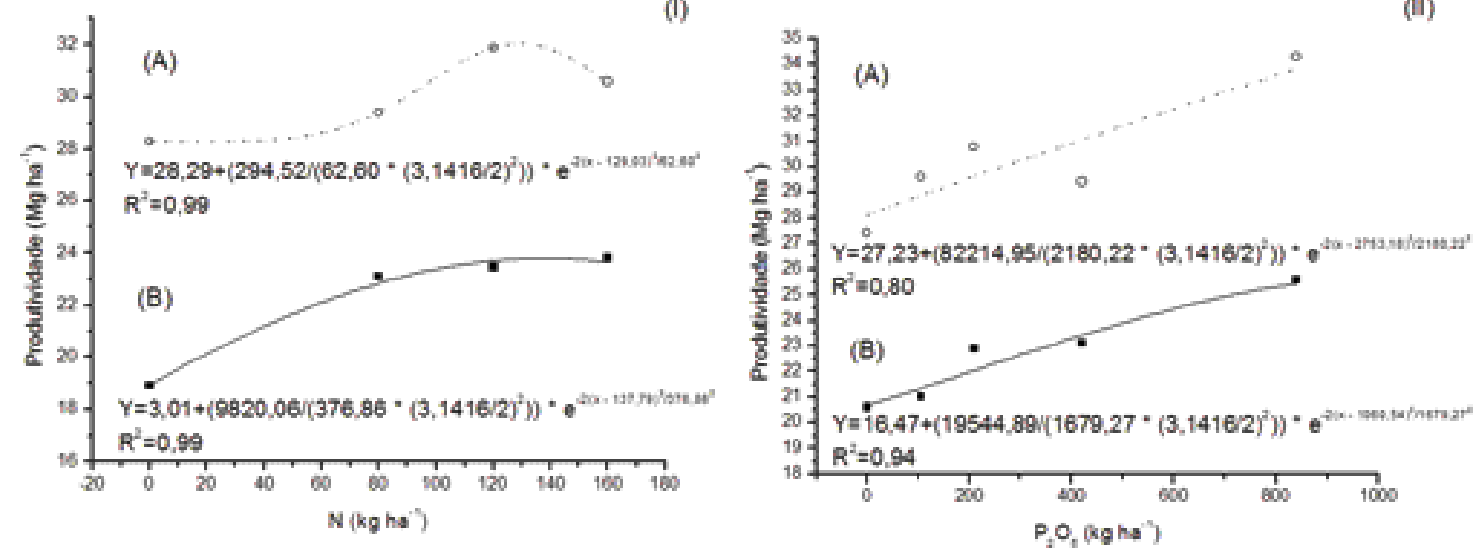

Figura 01. Curvas de respostas da cultura da batata resultantes da aplicação de diferentes doses de N (I) e P2O5 (II). No gráfico, (A) representa produtividade total e (B) produtividade comercial.

verifica-se que a máxima produtividade foi obtida com aplicação de $135 \mathrm{~kg} \mathrm{ha}^{-1}$, resultando em valores de 31,8 e 23,6 $\mathrm{Mg}_{\text {ha-1 }}$ para a produção de tubérculos não comerciais e comerciais, respectivamente. Observou-se a ocorrência de um maior número de tubérculos mal formados, com início de crescimento secundário, vulgarmente denominado de boneca, com presença de rachaduras e sintomas de podridão. Devem ser salienta-se os elevados valores na curva de produção relacionados à aplicação de nitrogênio parcelado (dose superior a $80 \mathrm{~kg} \mathrm{ha}^{-1}$ ).

$\mathrm{O}$ efeito positivo do nitrogênio sobre a produção da batata é relatado por JADOSKI et al. (2010). Contudo, RAIJ (1991) descreve que este nutriente quando aplicado em dosagens excessivas pode causar um desenvolvimento vegetativo exuberante, em detrimento da produção de tubérculos, o que pode, em parte, explicar o comportamento decrescente da curva de rendimento da cultura, a partir de dosagens superiores a $135 \mathrm{~kg}$ ha $^{-1}$.

Através destes resultados pode-se inferir que o aumento da adubação nitrogenada, de forma parcelada, em $80 \mathrm{~kg} \mathrm{ha}^{-1}$ no plantio e $40 \mathrm{~kg} \mathrm{ha}^{-1}$ em cobertura, está associado positivamente com a produtividade. Ressalta-se que este nutriente é componente de proteínas de fundamental importância no metabolismo da planta. Com destaque a rubisco, enzima mais abundante nas plantas, responsável pela fixação de $\mathrm{CO}_{2}$ na fase bioquímica da fotossíntese, promotora do acúmulo de carboidratos, e também das redutases e aminotransferases, enzimas importantes na incorporação do $\mathrm{N}$ e síntese de aminoácidos.
Para TAIZ e ZEIGER (2004) deve-se considerar a importância do equilíbrio dos nutrientes no solo e dos fatores sinérgicos, principalmente entre o nitrogênio e potássio.

Para a aplicação de fósforo, verificou-se aumento da produtividade com o incremento da dosagem aplicada do nutriente, obtendo-se os valores de 34,3 e 25,6 $\mathrm{Mg} \mathrm{ha}^{-1}$ para a produção não comercial e comercial, respectivamente (Figura 01-II). No entanto deve-se considerar que mesmo para doses mais elevadas, com produtividades maiores, essas respostas podem não resultar em ganhos econômicos efetivos devido a produtividade total apresentar quantidade crescente de tubérculos de diâmetro inferior a $45 \mathrm{~mm}$. Este é um um fator desejável em lavouras de produção de batata-semente. Tais respostas estão de acordo com WIERSEMA (1999) que demonstram a importância da disponibilidade de $\mathrm{P}_{2} \mathrm{O}_{5}$ para produção de tubérculos.

O comportamento da produção em função da aplicação de potássio na forma de $\mathrm{KCl}$ e de $\mathrm{K}_{2} \mathrm{SO}_{4}$ é apresentado na Figura 2. Verifica-se que a máxima produtividade alcançada de tubérculos comerciais $\left(24,5 \mathrm{Mg} \mathrm{ha}^{-1}\right)$ e não comerciais $\left(32,5 \mathrm{Mg} \mathrm{ha}^{-1}\right)$ é com a aplicação de doses de 390 e $240 \mathrm{~kg} \mathrm{ha}^{-1}$ de $\mathrm{KCl}$, respectivamente.

Através da avaliação do comportamento da curva de resposta da cultura às doses de $\mathrm{KCl}$, verificase que o incremento da quantidade aplicada, para valores superiores a $400 \mathrm{~kg} \mathrm{ha}^{-1}$, aproximadamente, está associado à reduções na produtividade. RAIJ (1991) relaciona este tipo de comportamento a aplicação da lei dos incrementos decrescentes, onde 

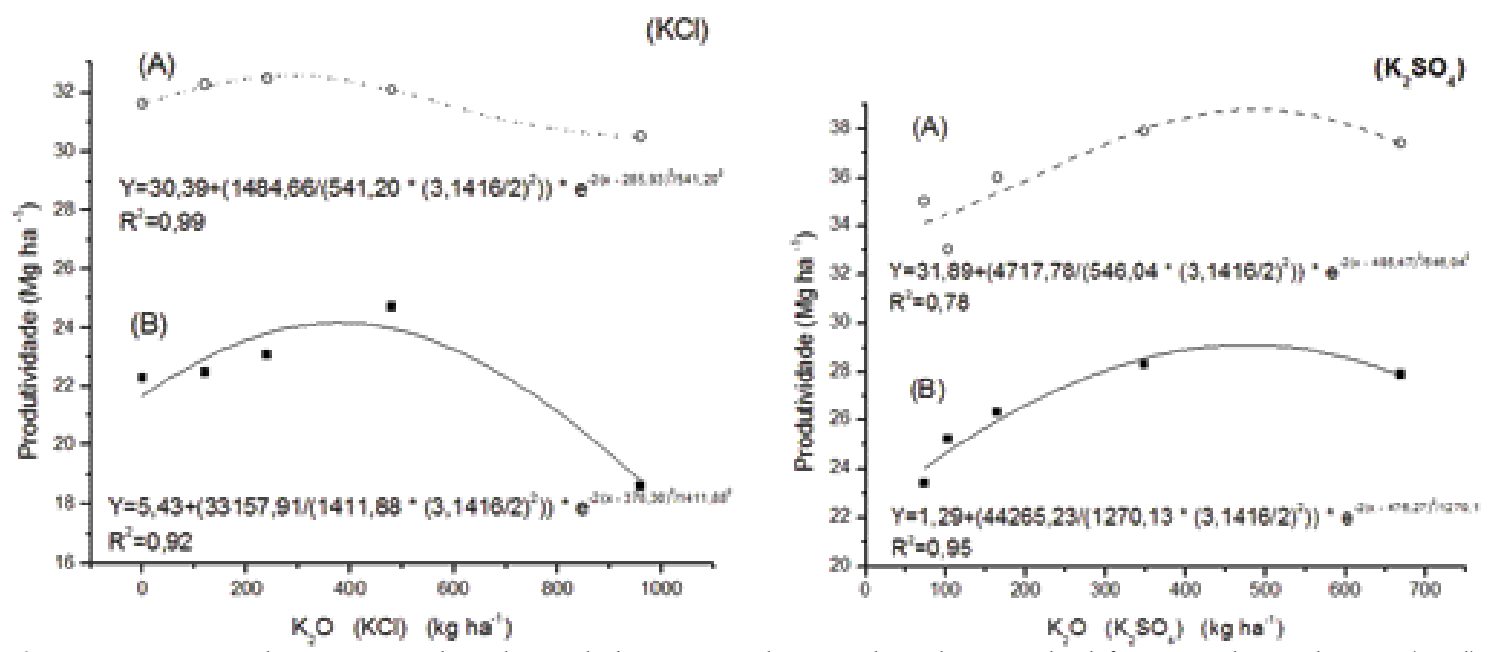

Figura 02. Curvas de respostas da cultura da batata resultantes da aplicação de diferentes doses de $\mathrm{K}_{2} \mathrm{O}(\mathrm{KCl})$ e $\mathrm{K}_{2} \mathrm{O}\left(\mathrm{K}_{2} \mathrm{SO}_{4}\right)$. No gráfico, (A) representa produtividade total e (B) produtividade comercial.

ocorre um efeito depressivo do nutriente sobre a cultura. Para MALAVOLTA e CROCOMO (1982) e ZEHLER (1981) o efeito tóxico do $\mathrm{Cl}$ prejudica o desenvolvimento das plantas, sendo que este micronutriente é exigido em pequenas quantidades pelo vegetal, e está associado a ocorrência de efeito deletério sobre às solanáceas. Desta forma, o estabelecimento da melhor dosagem do $\mathrm{KCl}$ é importante para a aplicação prática em áreas de produção tecnificadas.

Quando a adubação foi realizada utilizandose o potássio na forma de sulfato (K2SO4), foram verificados efeitos expressivos sobre o aumento da produtividade de tubérculos com doses crescentes até $500 \mathrm{~kg} \mathrm{ha}^{-1}$, resultando em produtividade de 29,2 e $38,8 \mathrm{Mg} \mathrm{ha}^{-1}$ de tubérculos comerciais e não comerciais, respectivamente. As quais são mais expressivamente superiores às verificadas com a aplicação de potássio na forma de $\mathrm{KCl}$.

Para Marschner (1993), resposta como esta em relação às doses crescentes de $\mathrm{K}_{2} \mathrm{SO}_{4}$ não devem ser avaliadas de forma isolada, mas sim, associadas a um provável efeito da ausência de $\mathrm{Cl}$ e presença de $\mathrm{S}$ na matéria prima. Inferências similares foram descritas por MENGUEL e KIRKBY (1987).

Na Figura 3 é apresentada a relação entre o custo de produção e a receita líquida para a cultura nas condições de realização do experimento. Para a dosagem de nitrogênio verifica-se que o investimento de $R \$ 9.172,00$ resulta em uma receita líquida de $\mathrm{R} \$ 5.220,00$ com a aplicação de $174 \mathrm{~kg}$ de $\mathrm{N} \mathrm{ha}^{-1}$.

A avaliação da aplicação de fósforo demonstra que a receita líquida apresentou comportamento crescente na faixa de adubação empregada, com valor máximo de $\mathrm{R} \$ 5.500,00$ para um investimento de $\mathrm{R} \$ 9.919,00$ com consumo de $918 \mathrm{~kg}$ de $\mathrm{P}_{2} \mathrm{O}_{5} \mathrm{ha}^{-1}$. Este resultado deve ser avaliado com cautela, devido ao baixo incremento de receita líquida verificado, especialmente, a partir de investimentos superiores a valores de aproximadamente $\mathrm{R} \$ 9.500,00 \mathrm{ha}^{-1}$.

Para a relação entre o custo de produção e a receita líquida devida à aplicação de potássio, verifica-se que quando a fonte utilizada foi o $\mathrm{KCl}$ a máxima receita líquida $\mathrm{R} \$ 5.200,00 \mathrm{ha}^{-1}$ é obtida com investimento de $\mathrm{R} \$ 9.235,00$ com consumo de $329 \mathrm{~kg}$ de $\mathrm{K}_{2} \mathrm{O}$ kg ha-1.

Quando a fonte de potássio utilizada foi o $\mathrm{K}_{2} \mathrm{SO}_{4}$ observa-se que o investimento de $\mathrm{R} \$ 9.830,00$ resulta em receita líquida de $\mathrm{R} \$ 7.280,00$, e o consumo do nutriente é de $559 \mathrm{~kg}$ de $\mathrm{K}_{2} \mathrm{O}_{\text {ha-1 }}$. Salienta-se que em relação ao uso de $\mathrm{KCl}$ o aumento de investimento de $6 \%$ está associado a um aumento de $28 \%$ na receita líquida da lavoura. RAIJ (1991) descreve que estudos desta natureza, relacionando custos de produção e receitas correspondentes, estão associados à denominada dose de eficiência econômica e são de fundamental importância para a agricultura.

\section{Conclusão}

A adubação potássica da cultura da batata na região Centro-Oeste do Estado do Paraná resulta na máxima receita líquida por área de cultivo quando a fórmula tradicional $120 \mathrm{~N}-420 \mathrm{P}_{2} \mathrm{O}_{5}-240 \mathrm{~K}_{2} \mathrm{O}(\mathrm{KCl})$ 


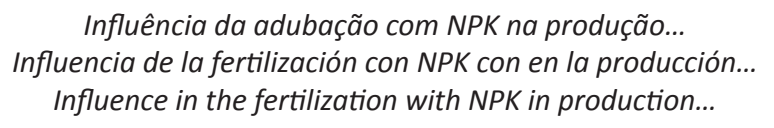

$\mathrm{kg} \mathrm{ha}^{-1}$ é ajustada para $120 \mathrm{~N}-420 \mathrm{P}_{2} \mathrm{O}_{5}-560 \mathrm{~K}_{2} \mathrm{O}$ $\left(\mathrm{K}_{2} \mathrm{SO}_{4}\right) \mathrm{kg} \mathrm{ha}^{-1}$.

A adubação nitrogenada com aplicação de 120 $\mathrm{kg}$ de $\mathrm{N} \mathrm{ha}^{-1}$ é uma alternativa com maior viabilidade quando o nutriente é aplicado $2 / 3$ na base e $1 / 3$ em cobertura.

A quantidade de fósforo deve levar em consideração o objetivo da lavoura, sendo que o aumento da dosagem favorece as lavouras de produção de batata-semente.

\section{Referências}

BEUKEMA, H.B.; ZAAG, D.E. Van der. Introduction to potato production. Wageningen - Netherlands: Pudac, 1990. 208 p.

CHAVES, L.H.G.; PEREIRA, H.H. Nutrição e adubação de tubérculos. Campinas: Fundação Cargill, 1985. 97 p.

COAMO. Fertilidade do solo e nutrição de plantas. Campo Mourão/Cascavel: Kromoset, 2001. 93 p.

CONTRERAS, A.M. Produccion de papa-semilla. Valdivia - Chile: Ediciones Quimei - Universidad Austral de Chile, 1994. 79 p.

FILGUEIRA, F.A.R. Nutrição mineral e adubação em bataticultura no Centro-Sul. In: Nutrição e Adubação de Hortaliças. Simpósio sobre Nutrição e Adubação de Hortaliças. Jaboticabal: Potafos, 1993. 401-427 p.

FONTES, P.C.R. Calagem e adubação da cultura da batata. In: Informe Agropecuário. Belo Horizonte - MG: EPAMIG, v.20, n¹, 1999. 128 p.

FONTES, P.C.R. Nutrição mineral e adubação. In: Produção de Batata. Brasília - DF: Linha Gráfica e Editora, 1987. $239 \mathrm{p}$.

FREIRE, C.J.S. Estudos na área de fertilidade do solo na cultura da batata no âmbito da Embrapa Clima Temperado. In: Anais da Reunião Técnica de Pesquisa e Extensão da Cultura da Batata da Região Sul do Brasil, 5., Pelotas: Embrapa Clima Temperado, 1998. p.30-37.

LUCCHESI, L.A.C. Fertilidade do solo. In: Curso Pós-Graduação Disciplina Fertilidade de Solo, UFPR. Curitiba - PR: 1999.

MAGALHÃES, J.R. Nutrição e adubação da batata. São Paulo - SP: Nobel, 1985. 51 p.

JADOSKI, S. O.; MAGGI, M. F.; LIMA, A. dos SANTOS; VIEIRA, D. J.; WAZNE, R. Avaliação da fórmula NPK 8-30-20 com adição de gesso agrícola em comparação à adubação convencional para produção de batata (Solanum tuberosum L.). Pesquisa Aplicada \& Agrotecnologia, v3, n.1, p.111-123, 2010.

MALAVOLTA, E.; CROCOMO, O.J.O Potássio e a planta. In: Simpósio sobre Potássio na Agricultura Brasileira em Londrina na Fundação IAPAR. 1.ed. Piracicaba: Instituto Potafos, 1982. p.95-162.

MARSCHNER, H. Mineral nutrition of higher plants. London: Academic Press. 1993. 674 p.

MENGUEL, K.; KIRBY, E.A. Principles of plant nutrition. 2. ed., Bern: Internacional Potash Institute, 1979. $593 \mathrm{p}$.

MONTALDO, A. Cultivo y mejoramiento de la papa. San José - Costa Rica: Livros Materiales Educativos. 1984. $232 \mathrm{p}$.

PEREIRA, A.P., DANIELS, J. O cultivo da batata na Região Sul do Brasil. Brasília - DF: Embrapa Informação Tecnológica, 2003. 567 p.

RAIJ, B. van, Fertilidade e adubação. Piracicaba-SP: Ceres, Potafós, 1991. 343 p.

REIFSCHNEIDER, F.S.B. Produção de batata. Brasília - DF: Linha Gráfica e Editora, 1987. 239 p.

STRUIK, P.C.; WIERSEMA, S.G. Seed potato technology. 1. ed. Wageningen - The Netherlands: Pers, 1999. $383 \mathrm{p}$.

TAIZ, L.; ZEIGER, E. Fisiologia vegetal. Traduzido por SANTARÉM, E. R. et al. 3.ed. Porto Alegre-RS:

Pesquisa Aplicada \& Agrotecnologia v4 n3 set/dez. (2011)

Print-ISSN 1983-6325 (On line) e-ISSN 1984-7548 
Mallmann et al. (2011)

Artemed, 2004. $719 \mathrm{p}$

ZAAG, D.E. van der. La patata y su cultivo en los Paises Bajos. Haya - Holanda: Instituto Consultivo Holandês sobre la Patata, 1993. 76 p.

ZAAG, P.V. Necessides de fertilidad de suelos para la producción de papa. CIP Montevideo: Editorial Hemisfério Sur S.R.L., 1986. 21 p.

ZEHLER, E. Potassium sulphate and potassium chloride: their influence on the yield and quality of cultivated plants. Worblanfen - Berna-Switzerland: Internacional Potash Institue, 1981. $111 \mathrm{p}$. 